\title{
A Probable Case of Mucosal Fixed Drug Eruption Following Treatment with Silodosin
}

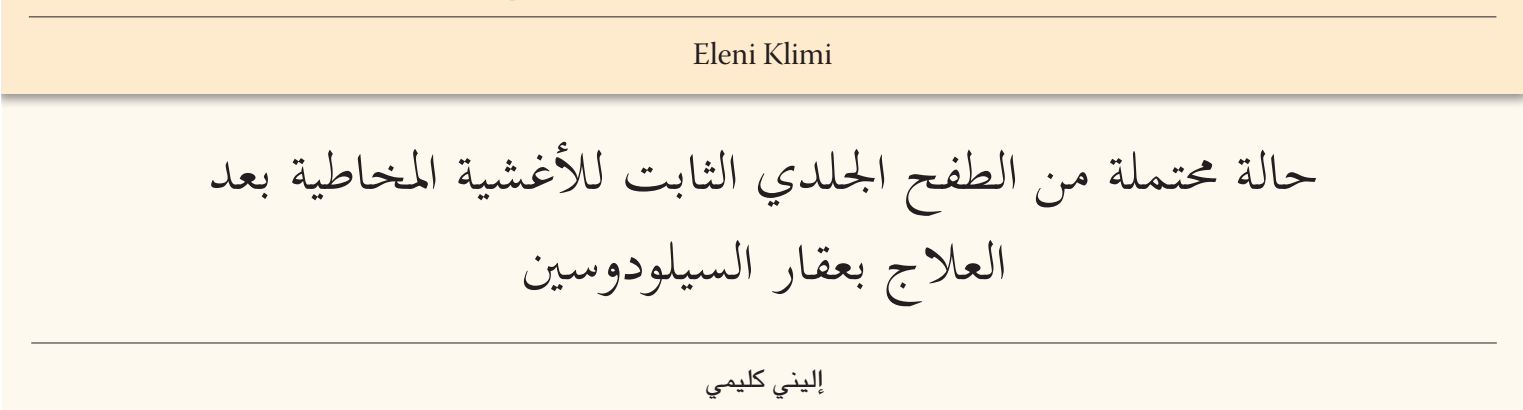

ABSTRACT: A fixed drug eruption consists of erythematous patches that appear on the skin and/or mucous membranes following administration of a drug which, once healed, leaves residual hyperpigmentation. We report a 76-year-old male who presented to the Thriasio General Hospital, Athens, Greece, in 2016 with erythema, oedema and blistering of the lower lip and glans penis following the administration of silodosin for benign prostatic hyperplasia. The eruption regressed two weeks after silodosin was discontinued.

Keywords: Drug Eruption; Mucous Membranes; Erythema; Blister; Silodosin; Case Report; Greece.

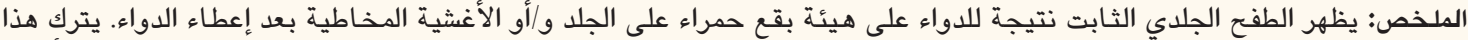

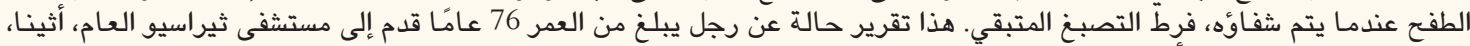

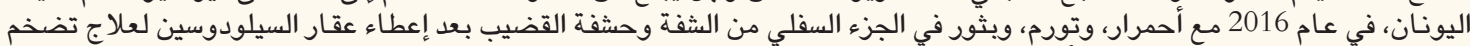

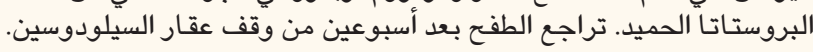

$$
\begin{aligned}
& \text { الكلمات المفتاحية: الطفح الجلدي نتيجة للدواء؛ الأغشية المخاطية؛ التهاب الجلد الإحمرارى؛ بثور؛ السيلودوسين؛ تقرير حالة؛ اليونان. }
\end{aligned}
$$

A FIXED DRUG ERUPTION (FDE) CONSISTS OF well-circumscribed erythematous patches on the skin and/or mucous membranes that occur between days and a few weeks following the administration of a drug. ${ }^{1}$ The patches recur on the same body site after the drug is reintroduced and heal leaving hyperpigmentation. Although the most common clinical presentation of FDE involves the skin, Zaouak et al. recently reported a case of mucosal FDE due to mefenamic acid. ${ }^{2}$ To the best of the author's knowledge, this is the first potential case of mucosal FDE following silodosin intake.

\section{Case Report}

A 76-year-old male presented to the dermatology outpatient clinic of the Thriasio General Hospital, Athens, Greece, in 2016 due to lesions on his lower lip and glans penis which had first appeared five days prior. Over the preceding 20 days, he reported having taken $8 \mathrm{mg}$ daily of silodosin as prescribed by his urologist for benign prostatic hyperplasia. He was not currently taking any other medications and had no history of atopy, immune disease or cancer.
A clinical examination revealed erythema and oedema of the lower lip and a well-circumscribed erythematous patch on the glans penis with a blister on one side [Figure 1]. The patient reported that a burning sensation had preceded the appearance of both lesions. A FDE was suspected; however, he refused a biopsy and a patch test. As a urologist confirmed that no further medication was needed in view of the minor nature of the patient's urinary symptoms, silodosin was discontinued. Within two weeks, regression of the lesions was observed [Figure 2]. Subsequently, a steroid cream of moderate potency was applied. A rechallenge protocol was not attempted as the patient was wary of the reappearance of the lesions.

\section{Discussion}

Overall, FDE is a rare type of adverse drug reaction. ${ }^{1}$ The clinical picture of a FDE involves a well-circumscribed erythematous patch on the skin and/or mucous membranes, with or without blisters, which recurs at the same site following the re-administration of the responsible drug and leaves hyperpigmentation after regression. In more severe cases, mucosal erosions or 


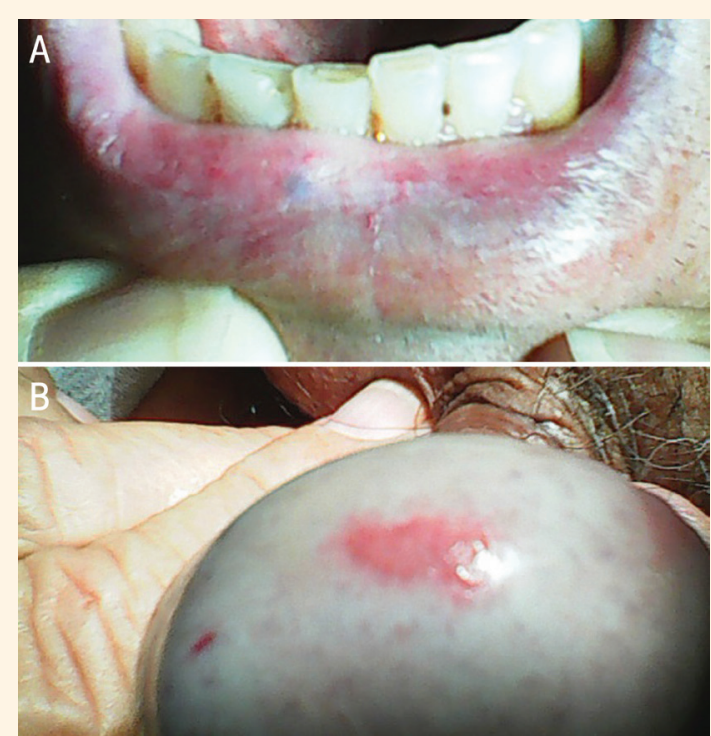

Figure 1: Clinical photographs of the (A) lower lip and (B) glans penis of a 76-year-old male showing erythema, oedema and blistering.

ulcerations may appear, resulting in a pseudo-aphthoid appearance. ${ }^{1}$ A FDE may appear as solitary or multiple lesions. ${ }^{3}$ Although the pigmented form is most common, a pure erythematous form as well as a rarer generalised bullous type imitating toxic epidermal necrolysis (TEN) has also been described. ${ }^{4,5}$ A histological analysis reveals a lichenoid reaction, keratinocyte necrosis, vacuolisation of the basal layer of the epidermis, dermal oedema and perivascular lymphohistiocytic and, occasionally, eosinophilic infiltrate with marked pigmentary incontinence between outbreaks. ${ }^{3}$

The differential diagnosis of FDE includes bullous impetigo in its initial stage, a herpes simplex virus infection, aphthous stomatitis, syphilis and autoimmune disorders such as bullous pemphigoid and pemphigus vulgaris. ${ }^{3}$ The main differential diagnosis is erythema multiforme which may also be drug-induced; however, the presence of typical target-like lesions in erythema multiforme helps to distinguish these two conditions. ${ }^{3}$ Non-steroidal anti-inflammatory drugs such as mefenamic acid, ibuprofen and oxyphenbutazone are a leading cause of FDEs, as well as antibiotics such as trimethoprim, tetracycline and sulfonamide. ${ }^{6}$ More rarely, meprobamate and oxcarbazepine have also been reported to induce FDEs. ${ }^{7,8}$

Intraepidermal resident cluster of differentiation (CD) $8^{+} \mathrm{T}$ cells have been implicated in the pathogenesis of FDE. ${ }^{9-11}$ When activated by certain stimuli, these cells release large amounts of inflammatory cytokines that induce inflammatory findings, such as erythema, blistering and ulceration. They also have memory and effector cell properties which are responsible for the recurrence of FDE lesions if the drug is reintroduced. ${ }^{9-11}$

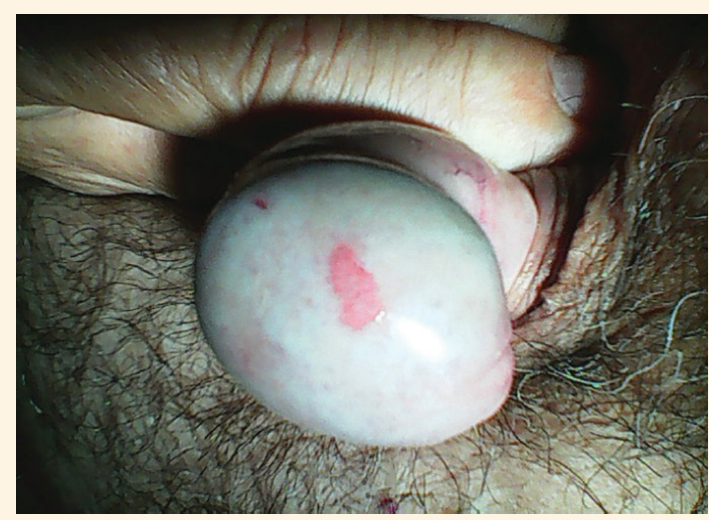

Figure 2: Clinical photograph of the glans penis of a 76year-old male with a suspected fixed drug eruption showing the regression of erythema following the discontinuation of silodosin.

On the other hand, intraepidermal CD8 ${ }^{+} \mathrm{T}$ cells function as protective immune cells against bacterial and viral infections. This explains why certain predilection sites for FDE, like the oral and genital mucosa, coincide with those of herpes simplex virus infections. ${ }^{9-11}$ The resolution of the FDE lesions occurs when regulatory $\mathrm{T}$ cells from other parts of the body are recruited at the affected site. This process accounts for the self-limiting nature of FDE in which the tissue damage is minor compared with the extensive and more destructive tissue damage seen in TEN cases. ${ }^{9-11}$

Silodosin, an alpha adrenergic receptor blocker, is commonly prescribed to relieve the urinary symptoms of benign prostatic hyperplasia. ${ }^{12}$ However, adverse skin reactions have been reported with its use, including pruritus, urticaria and maculopapular drug eruptions. ${ }^{13,14}$ According to the updated French causality assessment method, the likelihood of silodosin being the causative agent of FDE in the current case is suggestive, with an imputability value of I3. ${ }^{15}$ To the best of the author's knowledge, there have been no previous reports to date of mucosal FDE associated either with silodosin or similar drugs like tamsulosin.

\section{Conclusion}

The current case increases awareness of the potential occurrence of FDE following silodosin administration which could be easily misdiagnosed for other conditions. Drug intake history should therefore be taken into account in cases of genital and oral ulceration.

\section{References}

1. Flowers H, Brodell R, Brents M, Wyatt JP. Fixed drug eruptions: Presentation, diagnosis, and management. South Med J 2014; 107:724-7. doi: 10.14423/SMJ.0000000000000195. 
2. Zaouak A, Ben Brahim E, Ben Tanfous A, Koubaa W, Sahnoun R, Hammami H, et al. Mucosal fixed drug eruption due to mefenamic acid: Report of a case and a review. Therapie 2018; 73:433-5. doi: 10.1016/j.therap.2018.01.005.

3. Fitzpatrick TB, Johnson RA, Wolff K, Polano MK, Suurmond D. Fixed drug eruption. In: Color Atlas and Synopsis of Clinical Dermatology: Common and serious diseases, 3rd ed. New York, USA: McGraw-Hill Education, 1996. Pp. 560-3.

4. Ozkaya E, Elinç-Aslan MS. Pseudoephedrine may cause "pigmenting" fixed drug eruption. Dermatitis 2011; 22:E7-9. doi: $10.2310 / 6620.2011 .10119$.

5. Mitre V, Applebaum DS, Albahrani Y, Hsu S. Generalized bullous fixed drug eruption imitating toxic epidermal necrolysis: A case report and literature review. Dermatol Online J 2017; 23:7.

6. Hoetzenecker W, Nägeli M, Mehra ET, Jensen AN, Saulite I, Schmid-Grendelmeier P, et al. Adverse cutaneous drug eruptions: Current understanding. Semin Immunopathol 2016; 38:75-86. doi: 10.1007/s00281-015-0540-2.

7. Zaïem A, Kaabi W, Badri T, Lakhoua G, Sahnoun R, Kastalli S, et al. Meprobamate-induced fixed drug eruption. Curr Drug Saf 2014; 9:161-2. doi: 10.2174/1574886309666140121105737.

8. Shuster C, Kränke B, Aberer W, Komericki P. Fixed drug eruption on the penis due to oxcarbazepine. Arch Dermatol 2011; 147:362-4. doi: 10.1001/archdermatol.2011.32.
9. Shiohara T, Mizukawa Y. Fixed drug eruption: A disease mediated by self-inflicted responses of intraepidermal T cells. Eur J Dermatol 2007; 17:201-8. doi: 10.1684/ejd.2007.0149.

10. Shiohara T. Fixed drug eruption: Pathogenesis and diagnostic tests. Curr Opin Allergy Clin Immunol 2009; 9:316-21. doi: 10.10 97/ACI.0b013e32832cda4c.

11. Shiohara T, Mizukawa Y. Fixed drug eruption: The dark side of activation of intraepidermal CD8+ T cells uniquely specialized to mediate protective immunity. Chem Immunol Allergy 2012; 97:106-21 doi: 10.1159/000335623.

12. Keating GM. Silodosin: A review of its use in the treatment of the signs and symptoms of benign prostatic hyperplasia. Drugs 2015; 75:207-17. doi: 10.1007/S40265-014-0344-z.

13. Romano MV, Marino M, Cinconze M, Nasca MR, Furnari R, Petralia A, et al. Itching skin rash during valproic acid therapy in co-administration with silodosin: A case report and review of literature. J Clin Exp Dermatol Res 2016; 7:1000339. doi: 10.4172/2155-9554.1000339.

14. Inoue A, Sawada Y, Ohmori S, Omoto D, Haruyama S, Yoshioka M, et al. Maculopapular type drug eruption caused by silodosin. Allergol Int 2016; 65:219-20. doi: 10.1016/j.alit.2015.11.008.

15. Miremont-Salamé G, Théophile H, Haramburu F, Bégaud B. Causality assessment in pharmacovigilance: The French method and its successive updates. Therapie 2016; 71:179-86. doi: 10.1016/j. therap.2016.02.010. 